Case Report

\title{
Hepatitis E during Tocilizumab Therapy in a Patient with Rheumatoid Arthritis: Case Report and Literature Review
}

\author{
Hidekazu Ikeuchi $\mathbb{D}^{1},{ }^{1}$ Kana Koinuma, ${ }^{1}$ Masao Nakasatomi $\left(D,{ }^{1}\right.$ Toru Sakairi, ${ }^{1}$ \\ Yoriaki Kaneko, ${ }^{1}$ Akito Maeshima, ${ }^{1}$ Yuichi Yamazaki, ${ }^{2}$ Hiroaki Okamoto, ${ }^{3}$ \\ Toshihide Mimura $\mathbb{D}^{4}{ }^{4}$ Satoshi Mochida, ${ }^{5}$ Yoshihisa Nojima, ${ }^{6}$ and Keiju Hiromura $\mathbb{D}^{1}$ \\ ${ }^{1}$ Department of Nephrology and Rheumatology, Gunma University Graduate School of Medicine, Maebashi, Japan \\ ${ }^{2}$ Department of Medicine and Molecular Science, Gunma University Graduate School of Medicine, Maebashi, Japan \\ ${ }^{3}$ Division of Virology, Department of Infection and Immunity, Jichi Medical University School of Medicine, Shimotsuke, Japan \\ ${ }^{4}$ Department of Rheumatology and Applied Immunology, Faculty of Medicine, Saitama Medical University, Saitama, Japan \\ ${ }^{5}$ Division of Gastroenterology and Hepatology Internal Medicine, Saitama Medical University, Saitama, Japan \\ ${ }^{6}$ Department of Rheumatology and Nephrology, Japan Red Cross Maebashi Hospital, Maebashi, Japan
}

Correspondence should be addressed to Hidekazu Ikeuchi; hikeuchi@gunma-u.ac.jp

Received 9 February 2018; Accepted 27 June 2018; Published 26 July 2018

Academic Editor: Shigeko Inokuma

Copyright (C) 2018 Hidekazu Ikeuchi et al. This is an open access article distributed under the Creative Commons Attribution License, which permits unrestricted use, distribution, and reproduction in any medium, provided the original work is properly cited.

\begin{abstract}
Hepatitis $\mathrm{E}$ is an acute self-limiting disease caused by hepatitis E virus (HEV). Recent reports show that HEV can induce chronic hepatitis or be reactivated in immunocompromised hosts. We report a 63-year-old woman with rheumatoid arthritis (RA) who developed hepatitis E during treatment with tocilizumab. Analysis of serially stocked serum samples confirmed that hepatitis was caused by primary infection with HEV and not by viral reactivation. Her liver function improved after discontinuing tocilizumab and remained within the normal range without reactivation of $\mathrm{HEV}$ for $>5$ years after restarting tocilizumab. We also reviewed the published cases of hepatitis E that developed during RA treatment.
\end{abstract}

\section{Introduction}

Hepatic disorders are some of the most common complications that arise during rheumatoid arthritis (RA) treatment. Routine liver enzyme testing is recommended to detect the side effects of disease-modifying antirheumatic drugs (DMARDs) as well as the reactivation of viruses such as hepatitis type B (HBV), hepatitis type C (HCV), and cytomegalovirus $[1,2]$.

Hepatitis $\mathrm{E}$ is a disease of the liver that is caused by hepatitis type E virus (HEV) infection. HEV usually induces acute self-limiting hepatitis in healthy individuals. However, HEV is known to induce chronic hepatitis in immunocompromised hosts, including patients with HIV infection, chemotherapy recipients, and organ transplant recipients $[3,4]$. In addition, HEV deterioration has been reported in patients after allogenic stem cell transplantation $[5,6]$, despite low risk of deterioration [7].
Here, we report a case of hepatitis $\mathrm{E}$ that developed during tocilizumab therapy for RA. In this case, we sequentially determined the serum titers of HEV antibodies and RNA before and after the onset of hepatitis using stocked serum samples. In addition, we reviewed the published cases of hepatitis E that occurred during RA treatment with DMARDs.

\section{Case Presentation}

A 63-year-old woman visited our outpatient clinic because of general malaise that lasted 6 days. She developed RA at the age of 60 years and had been treated with $400 \mathrm{mg}$ monthly intravenous tocilizumab for the past 10 months and $3 \mathrm{mg} /$ day prednisolone. She had no history of blood transfusion, alcohol use, travel abroad, or raw meat intake, and her joints were not tender or swollen. Disease Activity Score 28 -joint count $\mathrm{C}$ reactive protein was 1.13 . Laboratory 
TABLE 1: Sequential changes of liver enzymes and laboratory tests for hepatitis E.

\begin{tabular}{|c|c|c|c|c|c|c|}
\hline Time after admission & $\begin{array}{c}\mathrm{AST} \\
\left(13-33 \mathrm{IU} / \mathrm{L}^{*}\right) \\
\end{array}$ & $\begin{array}{c}\text { ALT } \\
\left(6-27 \mathrm{IU} / \mathrm{L}^{*}\right) \\
\end{array}$ & $\begin{array}{l}\text { Anti-HEV IgG } \\
\left(\mathrm{OD}_{450}<0.175^{*}\right)\end{array}$ & $\begin{array}{l}\text { Anti-HEV IgM } \\
\left(\mathrm{OD}_{450}<0.440^{*}\right)\end{array}$ & $\begin{array}{c}\text { Anti-HEV IgA } \\
\left(\mathrm{OD}_{450}<0.642^{*}\right)\end{array}$ & $\begin{array}{c}\text { HEV RNA } \\
(-)\end{array}$ \\
\hline-30 months & 17 & 9 & 0.046 & 0.043 & 0.042 & - \\
\hline-20 months & 16 & 14 & 0.047 & 0.05 & 0.035 & - \\
\hline-10 months & 19 & 14 & 0.035 & 0.088 & 0.04 & - \\
\hline 0 & 338 & 523 & 2.563 & 2.845 & 2.93 & + \\
\hline 1 week & 44 & 137 & 2.822 & $>3.000$ & $>3.000$ & + \\
\hline 2 weeks & 32 & 37 & $>3.000$ & 2.894 & 2.296 & + \\
\hline 3 weeks & 22 & 18 & 2.748 & 2.771 & 1.499 & + \\
\hline 6 weeks & 27 & 25 & 2.956 & 2.661 & 1.113 & - \\
\hline 10 weeks & 22 & 15 & $>3.000$ & 2.303 & 1.019 & - \\
\hline 14 weeks & 27 & 19 & $>3.000$ & 1.863 & 0.799 & - \\
\hline 22 weeks & 43 & 28 & $>3.000$ & 1.022 & 0.536 & - \\
\hline 26 weeks & 31 & 26 & NA & NA & NA & NA \\
\hline 57 months & 24 & 17 & 1.659 & 0.176 & 0.115 & - \\
\hline
\end{tabular}

*Normal range. HEV, hepatitis E virus; IgG, immunoglobulin G; IgM, immunoglobulin M; IgA, immunoglobulin A; NA, not available.

data revealed elevated liver enzyme levels: AST, $338 \mathrm{IU} / \mathrm{L}$; ALT, 523 IU/L; ALP, 377 IU/L; and $\gamma$-GTP, 68 IU/L. Blood counts, total protein, albumin, total bilirubin, electrolytes, renal tests, $\mathrm{C}$ reactive protein, and coagulation test results were almost within normal ranges. Her serum HBV nucleic acid levels were monitored regularly to detect $\mathrm{HBV}$ reactivation because she tested positive for antibodies to $\mathrm{HBV}$ surface and core antigens without HBs antigen before the initiation of tocilizumab. At admission, HBV DNA levels were within normal range. Tests to detect antibodies to hepatitis $\mathrm{A}$ and $\mathrm{C}$ were negative. Tests to detect antibodies to Epstein-Barr virus and cytomegalovirus were both negative for immunoglobulin M (IgM) but positive for immunoglobulin G (IgG). Abdominal ultrasound revealed normal liver morphology.

The patient was diagnosed with HEV infection (genotype 3) because tests to detect anti-HEV immunoglobulin A (IgA) antibody and HEV RNA in her sera were both positive. Tocilizumab, pregabalin, eldecalcitol, and teriparatide were discontinued, and stronger neo-minophagen $\mathrm{C}$ and ursodeoxycholic acid were administered. Liver enzyme levels decreased and returned to normal 3 weeks after admission, and she was discharged from our hospital. Results of HEV RNA tests were negative 6 weeks after admission. Tocilizumab and eldecalcitol were reinitiated 4 weeks after liver enzyme normalization. RA remained in remission, and liver enzymes remained stable for the subsequent 5 years under tocilizumab therapy.

Because she had been a participant in a prospective clinical study to investigate the incidence of $\mathrm{HBV}$ reactivation in patients receiving immunosuppressive and/or anticancer therapies [8], her sera that was collected prior to hepatitis $\mathrm{E}$ onset had been stored. The use of serially stocked sera for HEV detection was approved by the Ethics Committee of Gunma University Hospital (\#15-61). We examined her serum for anti-HEV antibodies and HEV RNA before and after admission (Table 1). Neither anti-HEV antibodies nor HEV RNA was detected in the preadmission samples. In contrast, all of them were positive at admission. Anti-HEV IgM and IgA antibody levels peaked 1 week after admission and declined thereafter. Anti-HEV IgG antibody levels remained elevated until the final observation at 57 months. HEV RNA was detected at 0,2 , and 3 weeks after admission and was undetectable thereafter.

\section{Discussion}

HEV was previously believed to cause acute hepatitis but not chronic hepatitis. However, Kamar et al. first reported that chronic HEV infection was observed in patients after organ transplantation [3]. They further reported that $\mathrm{HEV}$ infection caused chronic hepatitis in $>60 \%$ of solid-organ transplant recipients [9]. Chronic HEV infection was also reported in patients with HIV infection and in a patient with malignant lymphoma treated with rituximab [4, 10]. In addition, HEV persistent infection has been reported in recipients of bone marrow transplant under severe immunosuppression [5-7]. Recently, biological DMARDs (bDMARDs) or targeted synthetic DMARDs (tsDMARDs) are frequently used in RA treatment. Treatment with bDMARDs is reported to increase the risk of hepatitis $B$ virus reactivation in patients with RA [11]. Therefore, chronic transformation of hepatitis $\mathrm{E}$ may occur in patients with RA who are treated with bDMARDs or tsDMARDs. In our case, sequential analysis of anti-HEV antibodies and HEV RNA using stocked serum samples clearly confirmed that our patient developed hepatitis as a result of primary acute HEV infection, but not recurrence or chronic infection of HEV. The clinical course of our patient was self-limiting, and the virus was eradicated from the serum without chronic transformation. In addition, there was neither recurrence of hepatitis nor persistent infection of HEV infection during the following 5 years, even after the reintroduction of tocilizumab.

The case reports of hepatitis $\mathrm{E}$ infection in patients with RA are accumulating [12-21]. Table 2 summarizes published cases of hepatitis E developed during the treatment of RA with DMARDs. Of 26 cases including ours, 20 were treated with bDMARDs or tsDMARDs with or without conventional synthetic DMARDs (csDMARDs) and 6 cases were treated with csDMARDs alone. Low-dose steroids were used in 16 cases. In most cases, DMARDs were discontinued for 


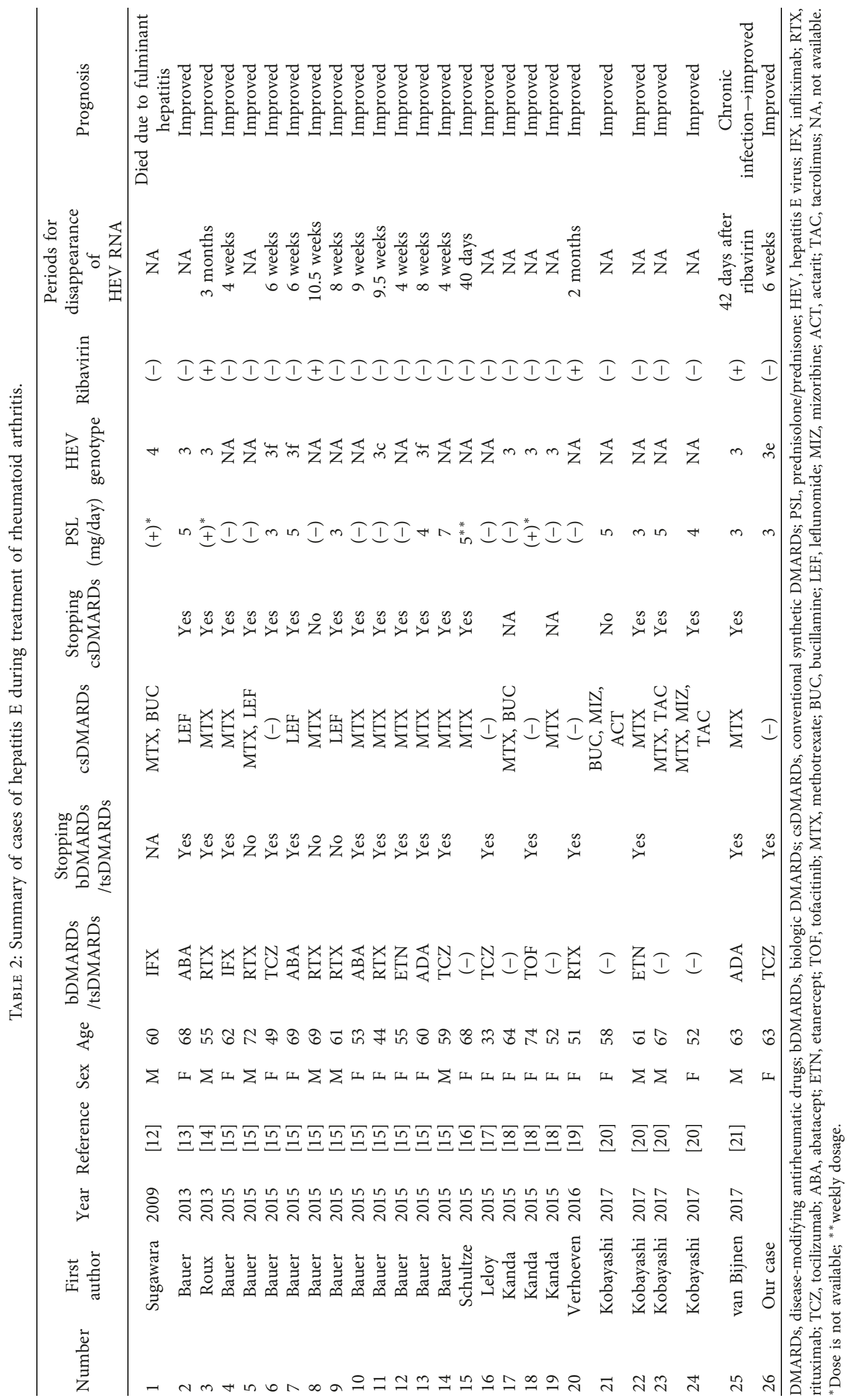


a certain period after the diagnosis of hepatitis. Temporal withdrawal of DMARDs may help the immune system to recover and eliminate $\mathrm{HEV}$. In most patients, liver function was normalized without antiviral therapy. However, 1 patient (case 1) died of fulminant hepatitis, despite treatment with plasma exchange and continuous hemofiltration [12]. The HEV genotype detected in this patient was genotype 4, which is known to be more virulent than genotype 3 . In addition, a male patient (case 25) who was administered adalimumab and methotrexate developed chronic hepatitis E [21]. The routine testing revealed elevated liver enzyme levels, and methotrexate, but not adalimumab, was discontinued. Eight months later, he was diagnosed with HEV infection, and adalimumab was discontinued. However, serum HEV RNA remained positive for more than 5 months; therefore, he was treated with ribavirin for 42 days until the test results for serum HEV RNA were negative [21].

In transplant recipients with chronic HEV infection, antiviral therapy with interferon- $\alpha$ and ribavirin as monotherapy or in combination is recommended if immunosuppressive therapy has to be continued or viral clearance is difficult to achieve even after weakening immunosuppression $[22,23]$. In patients with RA who are treated with DMARDs as listed above, only 4 cases were treated with ribavirin and 3 of them had been treated with rituximab. Another patient had been treated with adalimumab before and after notification of elevated liver enzymes for several months and ultimately developed chronic hepatitis E, as described above $[14,15,19,21]$. Based on these results, antiviral therapy may be considered only in high-risk patients: patients with HEV (genotype 4), those who had been treated with long-lasting and immunosuppressive DMARDs such as rituximab, and those with severe or chronic hepatitis. Further investigation is to clarify the adequate use of ribavirin in acute hepatitis E patients taking DMARDs.

In summary, we presented a case of RA with hepatitis E that developed during tocilizumab therapy, and we reviewed published cases of hepatitis $\mathrm{E}$ among patients with RA on DMARDs treatment. In RA patients whose liver dysfunction was detected at routine examination, the possibility of HEV infection should be considered. In a case of hepatitis E, discontinuation of bDMARDs or tsDMARDs is recommended, and administration of ribavirin may be necessary in high-risk patients. In addition, in our case, tocilizumab was safely used after normalization of liver function for a long term without persistent infection of HEV.

\section{Consent}

The patient's written informed consent for publication of information about her was obtained.

\section{Disclosure}

Parts of this manuscript were reported in Kanto Riumachi (2016; 1: 96-102) in Japanese, from the proceedings of the 47th Kanto Riumachi Conference (Tokyo, Japan).

\section{Conflicts of Interest}

Keiju Hiromura has received an honoraria for lectures from Chugai Pharmaceutical, Co., Ltd. Satoshi Mochida has received an honoraria for lectures from Bristol-Myers Squibb, consigned/joint research expenses from Bristol-Myers Squibb and Tanabe Mitsubishi Pharma Co., and scholarship donations from Bristol-Myers Squibb, Chugai Pharmaceutical Co. Ltd., Eisai Co. Ltd., and Takeda Pharmaceutical Co. Ltd. The authors declare that they have no conflicts of interest.

\section{References}

[1] K. G. Saag, G. G. Teng, N. M. Patkar et al., “American College of Rheumatology 2008 recommendations for the use of nonbiologic and biologic disease-modifying antirheumatic drugs in rheumatoid arthritis," Arthritis and Rheumatism, vol. 59, no. 6, pp. 762-784, 2008.

[2] J. A. Singh, K. G. Saag, S. L. Bridges Jr. et al., "2015 American College of Rheumatology Guideline for the Treatment of Rheumatoid Arthritis," Arthritis and Rheumatology, vol. 68, no. 1, pp. 1-26, 2016.

[3] N. Kamar, J. Selves, J. M. Mansuy et al., "Hepatitis E virus and chronic hepatitis in organ-transplant recipients," New England Journal of Medicine, vol. 358, no. 8, pp. 811-817, 2008.

[4] H. R. Dalton, R. P. Bendall, F. E. Keane, R. S. Tedder, and S. Ijaz, "Persistent carriage of hepatitis E virus in patients with HIV infection," The New England Journal of Medicine, vol. 361, no. 10, pp. 1025-1027, 2009.

[5] P. le Coutre, H. Meisel, J. Hofmann et al., "Reactivation of hepatitis $\mathrm{E}$ infection in a patient with acute lymphoblastic leukaemia after allogeneic stem cell transplantation," Gut, vol. 58, no. 5, pp. 699-702, 2009.

[6] J. Versluis, S. D. Pas, H. J. Agteresch et al., "Hepatitis E virus: an underestimated opportunistic pathogen in recipients of allogeneic hematopoietic stem cell transplantation," Blood, vol. 122, no. 6, pp. 1079-1086, 2013.

[7] F. Abravanel, J. M. Mansuy, A. Huynh et al., "Low risk of hepatitis E virus reactivation after haematopoietic stem cell transplantation," Journal of Clinical Virology, vol. 54, no. 2, pp. 152-155, 2012.

[8] S. Mochida, M. Nakao, N. Nakayama et al., "Nationwide prospective and retrospective surveys for hepatitis B virus reactivation during immunosuppressive therapies," Journal of Gastroenterology, vol. 51, no. 10, pp. 999-1010, 2016.

[9] N. Kamar, C. Garrouste, E. B. Haagsma et al., "Factors associated with chronic hepatitis in patients with hepatitis $\mathrm{E}$ virus infection who have received solid organ transplants," Gastroenterology, vol. 140, no. 5, pp. 1481-1489, 2011.

[10] L. Ollier, N. Tieulie, F. Sanderson et al., "Chronic hepatitis after hepatitis E virus infection in a patient with non-Hodgkin lymphoma taking rituximab," Annals of Internal Medicine, vol. 150 , no. 6 , pp. 430-431, 2009.

[11] Y. Urata, R. Uesato, D. Tanaka et al., "Prevalence of reactivation of hepatitis B virus replication in rheumatoid arthritis patients," Modern Rheumatology, vol. 21, no. 1, pp. 16-23, 2011.

[12] N. Sugawara, A. Yawata, K. Takahashi, N. Abe, and M. Arai, "The third case of fulminant hepatitis associated with "Kitami/ Abashiri strain" of hepatitis E virus genotype 4," Kanzo, vol. 50, no. 8, pp. 473-374, 2009. 
[13] H. Bauer, J. Sibilia, P. Moreau, and L. Messer, "Acute hepatitis E during biotherapy," Joint Bone Spine, vol. 80, no. 1, pp. 91-92, 2013.

[14] C.H. Roux, R. Anty, S. Patouraux, and L. Euller-Ziegler, "Hepatitis E: are rheumatic patients at risk?," Journal of Rheumatology, vol. 40, no. 1, p. 99, 2013.

[15] H. Bauer, C. Luxembourger, J. E. Gottenberg et al., "Outcome of hepatitis $\mathrm{E}$ virus infection in patients with inflammatory arthritides treated with immunosuppressants: a French retrospective multicenter study," Medicine, vol. 94, no. 14, p. e675, 2015.

[16] D. Schultze, B. Mani, G. Dollenmaier, R. Sahli, A. Zbinden, and P. A. Krayenbuhl, "Acute Hepatitis E Virus infection with coincident reactivation of Epstein-Barr virus infection in an immunosuppressed patient with rheumatoid arthritis: a case report," BMC Infectious Diseases, vol. 15, no. 1, p. 474, 2015.

[17] M. Leroy, G. Coiffier, C. Pronier, L. Triquet, A. Perdriger, and P. Guggenbuhl, "Macrophage activation syndrome with acute hepatitis E during tocilizumab treatment for rheumatoid arthritis," Joint Bone Spine, vol. 82, no. 4, pp. 278-279, 2015.

[18] T. Kanda, S. Yasui, M. Nakamura et al., "Recent trend of hepatitis $\mathrm{E}$ virus infection in Chiba area, Japan: 3 of 5 cases with rheumatoid arthritis," Case Reports in Gastroenterology, vol. 9, no. 3, pp. 317-326, 2015.

[19] F. Verhoeven, D. Weil-Verhoeven, V. Di Martino, C. Prati, T. Thevenot, and D. Wendling, "Management of acute HVE infection in a patient treated with rituximab for rheumatoid arthritis," Joint Bone Spine, vol. 83, no. 5, pp. 577-578, 2016.

[20] D. Kobayashi, S. Ito, C. Takai et al., "Type-E hepatitis in rheumatoid arthritis patients," Modern Rheumatology Case Reports, vol. 1, no. 2, pp. 30-34, 2017.

[21] S. T. van Bijnen, M. Ledeboer, and H. A. Martens, "Chronic hepatitis $\mathrm{E}$ in a patient with rheumatoid arthritis treated with adalimumab and methotrexate," Rheumatology, vol. 56, no. 3, pp. 497-498, 2017.

[22] N. Kamar, R. Bendall, F. Legrand-Abravanel et al., "Hepatitis E," The Lancet, vol. 379, no. 9835, pp. 2477-2488, 2012.

[23] N. Kamar, J. Izopet, S. Tripon et al., "Ribavirin for chronic hepatitis E virus infection in transplant recipients," New England Journal of Medicine, vol. 370, no. 12, pp. 1111-1120, 2014. 


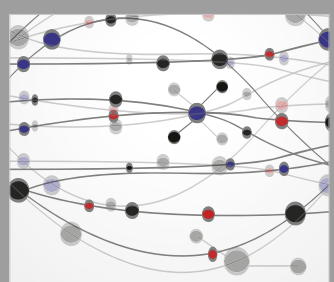

The Scientific World Journal
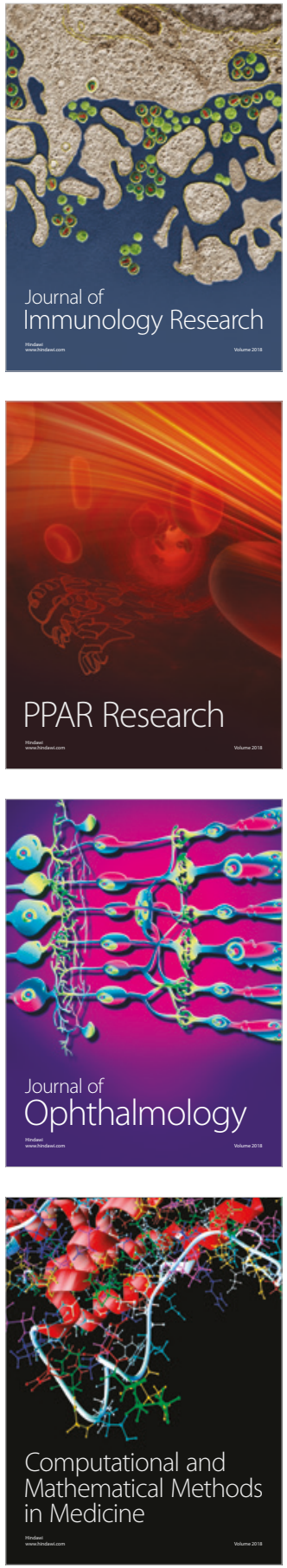

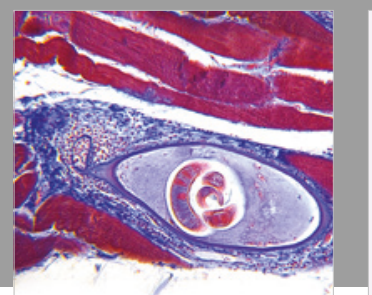

Gastroenterology Research and Practice

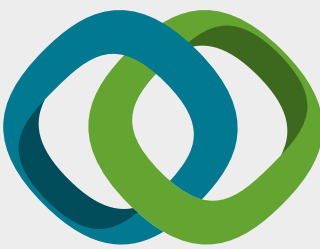

\section{Hindawi}

Submit your manuscripts at

www.hindawi.com
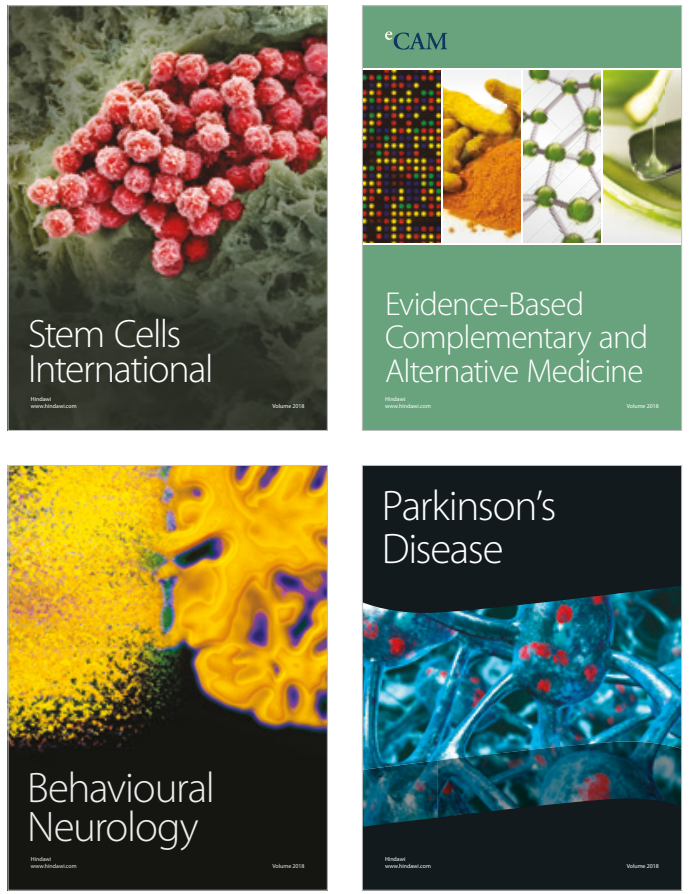

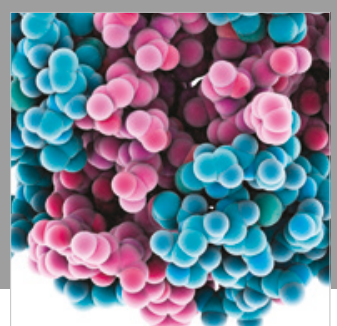

ournal of

Diabetes Research

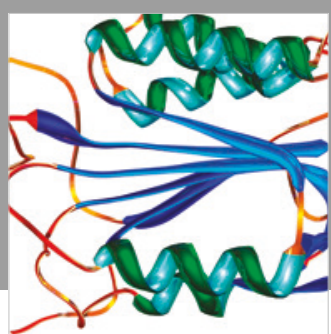

Disease Markers
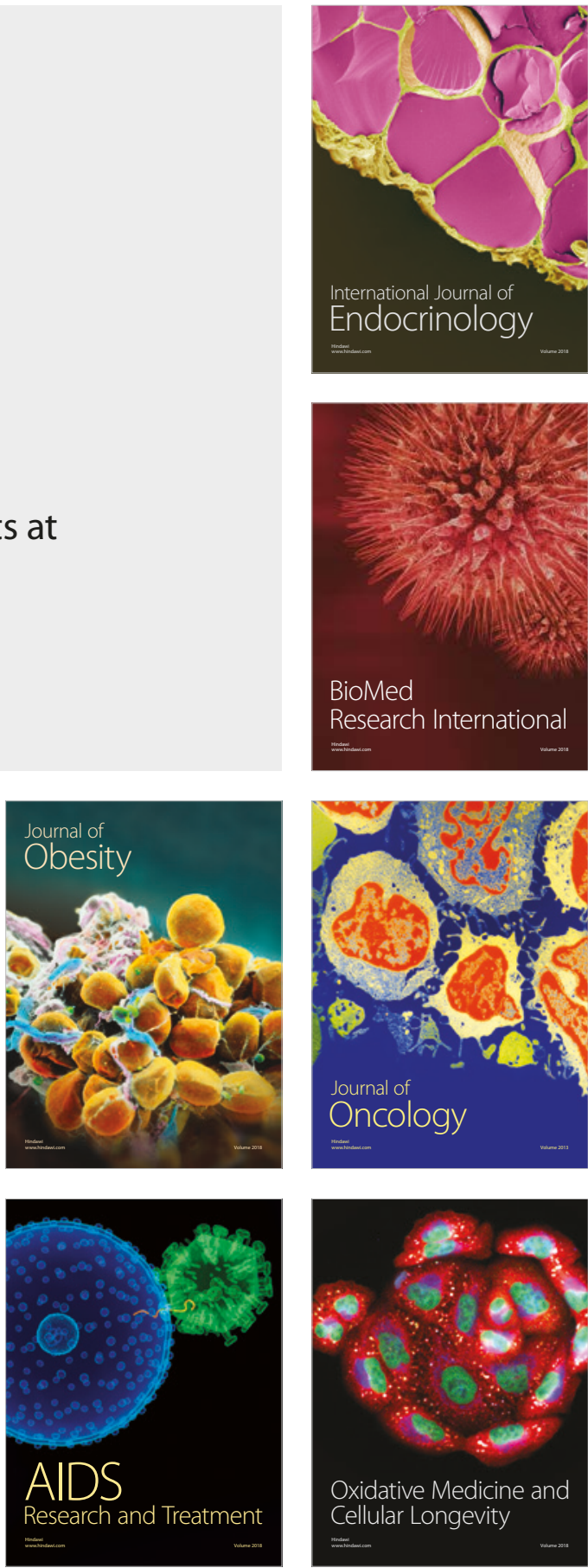